\title{
Characterization of impregnated GDC nano structures and their functionality in LSM based cathodes
}

Klemensø, Trine; Chatzichristodoulou, Christodoulos; Nielsen, Jimmi; Bozza, Francesco; Thydén, Karl Tor Sune; Kiebach, Wolff-Ragnar; Ramousse, Severine

Published in:

Solid State lonics

Link to article, DOI:

10.1016/j.ssi.2012.07.011

Publication date:

2012

Document Version

Publisher's PDF, also known as Version of record

Link back to DTU Orbit

Citation $(A P A)$ :

Klemensø, T., Chatzichristodoulou, C., Nielsen, J., Bozza, F., Thydén, K. T. S., Kiebach, W-R., \& Ramousse, S. (2012). Characterization of impregnated GDC nano structures and their functionality in LSM based cathodes. Solid State lonics, 224, 21-31. https://doi.org/10.1016/j.ssi.2012.07.011

\section{General rights}

Copyright and moral rights for the publications made accessible in the public portal are retained by the authors and/or other copyright owners and it is a condition of accessing publications that users recognise and abide by the legal requirements associated with these rights.

- Users may download and print one copy of any publication from the public portal for the purpose of private study or research.

- You may not further distribute the material or use it for any profit-making activity or commercial gain

- You may freely distribute the URL identifying the publication in the public portal 


\title{
Characterization of impregnated GDC nano structures and their functionality in LSM based cathodes
}

\author{
Trine Klemensø ${ }^{*}$, Christodoulos Chatzichristodoulou, Jimmi Nielsen, Francesco Bozza, Karl Thydén, \\ Ragnar Kiebach, Severine Ramousse
}

Department of Energy Conversion and Storage, Technical University of Denmark, Risø Campus, Frederiksborgvej 399, DK-4000 Roskilde, Denmark

\section{A R T I C L E I N F O}

\section{Article history:}

Received 7 May 2012

Received in revised form 28 June 2012

Accepted 16 July 2012

Available online 3 August 2012

\section{Keywords:}

Solid oxide fuel cell electrode

Impregnation

Infiltration

Nano particle

Triple phase boundary

Meso porous materials

\begin{abstract}
A B S T R A C T
Porous composite cathodes of LSM-YSZ (lanthanum strontium manganite and yttria stabilized zirconia) were impregnated with GDC (gadolinia doped ceria) nano particles. The impregnation process was varied using none or different surfactants (Triton X-45, Triton X-100, P123), and the quantity of impregnated GDC was varied via the precursor concentration and number of impregnation cycles. The obtained structures were characterized with $\mathrm{Kr}$ and $\mathrm{N}_{2}$ adsorption/desorption isotherms, mercury intrusion porosimetry, in-situ high temperature X-ray diffraction, scanning electron microscopy (SEM) and electrochemical impedance spectroscopy (EIS). The performance of the impregnated LSM-YSZ cathode was correlated with the GDC load, and the density and connectivity of the GDC phase, whereas crystallite size and surface area appeared less significant. The impregnated GDC was indicated to be preferentially situated on the LSM phase and the LSM grain boundaries. The observations suggest that the improved performance associated with GDC nano particles is related to the particles placed near the TPB (triple phase boundary) zone. The GDC extends the TPB by creating an ionic conducting network on top of the LSM particles and on top of the insulating low conducting zirconates at the LSM-YSZ interface.
\end{abstract}

(c) 2012 Elsevier B.V. All rights reserved.

\section{Introduction}

The impregnation or infiltration with nano particles is an increasingly applied method to improve the electrochemical performance of electrode materials, particularly in SOFC (solid oxide fuel cell) electrodes. The terms impregnation and infiltration are used interchangeably, but with a tendency to use impregnation when introducing lower loadings into the electrode, as e.g. done in heterogeneous catalysis, and infiltration when higher loadings and percolating phases are formed in the process. As both approaches are used in the literature for electrodes, as well as in this study, the terms will be used synonymously.

A vast number of electrode backbones impregnated with a large variation of impregnation compositions have been investigated, and several reviews in the field exist, most recently by Jiang et al. [1] on SOFC cathode impregnation, and S.P. Jiang [2] on SOFC electrodes. Despite the extensive research in the area, the functionality of the nano particles is not yet fully understood. The apparent discrepancies in the literature are described in detail in the reviews and summarized in the following. In many cases, the infiltrated nano particles provide enhanced ionic conductivity to the structure, thereby increasing the active TPB (triple phase boundary) zone. This is believed to be the case in LSM backbones

\footnotetext{
* Corresponding author. Tel.: +45 46775756.

E-mail address: trkl@dtu.dk (T. Klemensø).
}

infiltrated with YSB (yttria stabilized bismuth oxide) or GDC. Better performance is observed with higher loadings of GDC [3,4], and with YSB which has a higher oxide ion conductivity than GDC [1].

However, for several impregnated systems, a similar effect is observed irrespective of differences in the oxide ion conductivity of the impregnated nano particles. This is especially seen for systems where the impregnated backbone is a composite possessing both ionic and electronic conductivities. For example, LSM-YSZ composite cathodes infiltrated with $\mathrm{CeO}_{2}$ or doped ceria have shown similar performance [1]. Also, similar performance was observed for YSZ-LSM or YSZ-LSF infiltrated electrodes, which were further impregnated with $\mathrm{Pd}, \mathrm{CeO}_{2}$, SDC (samaria doped ceria), YSZ, $\mathrm{CaO}$, or $\mathrm{K}_{2} \mathrm{O}$, despite the impregnated materials differing widely in oxide ion conductivity and catalytic activity [1]. Most recently, Liu et al. [5] studied Ni-based anodes impregnated with SDC, $\mathrm{CeO}_{2}, \mathrm{Sm}_{2} \mathrm{O}_{3}$ or $\mathrm{Al}_{2} \mathrm{O}_{3}$ and showed that similar performance was obtained for all the materials except for $\mathrm{Al}_{2} \mathrm{O}_{3}$, despite the differences in oxide ion conductivity.

The later observations point to the nano particles having a more structural effect than pure extension of the TPB or only catalytic nature. Among the suggested explanations are the nano particles acting as impurity scavengers, and the effect being more a function of their size than the material [1,6]. Bidrawn et al. [1,7] suggested surface area modification by the nano particles, irrespective of the material properties, which could explain the similar performance enhancement. Also recently, it was shown that the impregnation precursor solution can chemically modify the electrode surface [8]. Another, or an additional mechanism 
associated with the nano particles, could be enhanced catalytic effect known as NEMCA from catalysis [9] or spillover mechanism [10].

A key to further understanding of the impregnation effect is characterization of the formed nano structures, which will be the focus of the current study. In this work, LSM-YSZ cathodes impregnated with GDC are taken as example. The impregnated material is restricted to GDC, and the microstructure of the impregnated phase is varied by using impregnation precursors of different concentrations and with different surfactants, and different loads of infiltrated GDC. The microstructures are characterized, and the effect of the nano structure is discussed with respect to the electrical and electrochemical performance.

\section{Experimental}

\subsection{Sample preparation}

Symmetrical cells were prepared by screen printing the composite cathode of 50/50 wt.\% $\mathrm{La}_{0.75} \mathrm{Sr}_{0.25} \mathrm{Mn}_{1.05} \mathrm{O}_{3 \pm \delta}$ (LSM25) and $\mathrm{Zr}_{0.84} \mathrm{Y}_{0.16} \mathrm{O}_{1.92}$ (8YSZ) onto both sides of a $16 \mathrm{~cm}^{2}$ sintered $8 \mathrm{YSZ}$ electrolyte layer. The electrolyte was produced in-house by tape casting and had a post-sintered thickness of ca. $200 \mu \mathrm{m}$. After printing, the cathodes were sintered above $1000{ }^{\circ} \mathrm{C}$. The sintered $16 \mathrm{~cm}^{2}$ cells were used for analyses of the specific surface area and pore size distribution (gas sorption), mercury intrusion porosimetry, electron microscopy and X-ray diffraction, before and after impregnation. Some of the $16 \mathrm{~cm}^{2}$ cells were further cut into $6 \times 6 \mathrm{~mm}^{2}$ samples for electrochemical cell testing. The smaller cells were painted with gold paste (Ferro) and sintered above $850{ }^{\circ} \mathrm{C}$ before impregnation.

Impregnation solutions with low GDC precursor concentration (LC) and high concentration (HC), and with and without surfactants were prepared and are summarized in Table 1 . The impregnation solutions were prepared by dissolving $\mathrm{Gd}\left(\mathrm{NO}_{3}\right)_{3} \cdot 6 \mathrm{H} 2 \mathrm{O}$ (Alfa Aesar) and $\mathrm{Ce}\left(\mathrm{NO}_{3}\right)_{3} \cdot 6 \mathrm{H}_{2} \mathrm{O}$ (Alfa Aesar) at a mole ratio of $1: 4$ in ultrapure water. In some of the solutions, a surfactant was added, which was either Triton X-100 (Sigma Aldrich), Pluronic P123 (BASF), or Triton X-45 (Fluka), and the surfactants will be denoted S1, S2 and S3, respectively, as shown in Table 1. A surfactant concentration of 0.4-0.6 g per $10 \mathrm{~g}$ water was chosen, which is believed to be a factor of ca. 10 to 100 above the critical micelle concentration (CMC) for the surfactant. The CMC and the micelle properties are to a high degree dependent on the temperature, and the components in the solution as well as their concentrations. Therefore, a significant spread in the reported values exists. The reported CMC values for Triton X-100 are between 0.103 and $0.6 \mathrm{mg} / \mathrm{mL}$ [11-15], for Triton X-45 between 0.04 and $0.057 \mathrm{mg} / \mathrm{mL}$ [13-15], and for P123 between 0.04 and $0.4 \mathrm{mg} / \mathrm{mL}$ $[16,17]$. The solutions were prepared at ambient temperature, which is believed to be above the Krafft temperature for P123, where self-assembly is observed [16]. For Triton X-100, ambient temperature also appeared to be above the Krafft point as the prepared solutions were transparent. However, the solution with Triton X-45 was milky at room temperature in accordance with a reported Krafft

\section{Table 1}

Impregnation solutions (precursors) and samples tested. The nomenclature is based on the surfactant type ( $\mathrm{S} 1$ is Triton X-100, S2 is P123, S3 is Triton X-45), and the GDC load contained in the precursor ( $\mathrm{LC}$ is low concentration, $\mathrm{HC}$ is high concentration) reflected as the amount of GDC impregnated in one step relative to the backbone (shown in wt.\% and $\mathrm{mg} / \mathrm{m}^{2}$ backbone in the table).

\begin{tabular}{lllrr}
\hline Name & Surfactant type & $\begin{array}{l}\text { Surfactant concentration } \\
\text { in } \mathrm{g} / 10 \mathrm{~g} \mathrm{H}_{2} \mathrm{O}\end{array}$ & GDC in wt.\% & GDC in $\mathrm{mg} / \mathrm{m}^{2}$ \\
& & - & $3.3 \pm 0.3$ & $10.6 \pm 1.0$ \\
\hline LC & None & 0.6 & $3.1 \pm 0.3$ & $9.7 \pm 1.0$ \\
LC-S1 & Triton X-100 & - & $12.0 \pm 1.2$ & $38.1 \pm 3.8$ \\
HC & None & 0.6 & $11.4 \pm 1.4$ & $36.1 \pm 3.6$ \\
HC-S1 & Triton X-100 & 0.6 & $12.9 \pm 1.3$ & $40.8 \pm 4.1$ \\
HC-S2 & P123 & 0.6 & $9.9 \pm 1.0$ & $31.3 \pm 3.1$ \\
HC-S3 & Triton X-45 & 0.4 & & \\
\hline
\end{tabular}

point of $35{ }^{\circ} \mathrm{C}$ [13]. At higher temperatures, the Tritons can again become insoluble at the cloud point, which is reported to be $38{ }^{\circ} \mathrm{C}$ for Triton X-45, and $64-68.5{ }^{\circ} \mathrm{C}$ for Triton X-100 [11,13]. The impregnation was carried out by dripping an excess of the solution onto the sample and drying in a vacuum chamber, before heating abruptly to $300{ }^{\circ} \mathrm{C}$ to form the GDC phase. To obtain higher GDC loadings, the impregnation process was repeated.

Some of the precursors were examined by in-situ high temperature X-ray diffraction (HT-XRD) to follow the formation and growth of the crystalline phases. This was done by dripping the solution on top of a Pt foil and heating from room temperature to $900{ }^{\circ} \mathrm{C}$ with diffraction patterns recorded every $50-100{ }^{\circ} \mathrm{C}$.

The conductivity of the impregnated GDC phase was evaluated by measurements on an infiltrated model YSZ backbone. Since the conductivity of the LSM-YSZ backbone is dominated by the electronic conductivity of LSM, it is difficult to distinguish the contribution of the infiltrated GDC phase. Instead, porous samples of 8YSZ were fabricated and infiltrated with a precursor, and the total conductivity was measured before and after infiltration by impedance spectroscopy. The porous $8 Y S Z$ samples were fabricated from a tape cast slurry containing graphite as pore former and sintered to an open porosity of $27 \%$ (see [18] for details). Sintered Au paste was used as current collector as described earlier.

Dense pellets were prepared to examine the 2-dimensional structure of the impregnated GDC. The samples were made by dripping precursor solution onto the surface of a LSM-YSZ pellet. The pellets were prepared by mixing the two powders, LSM25 and 8YSZ (50:50 wt.\% ratio), and uniaxially press-forming the powder into disks. The pressed pellets were sintered at 1300 or $1500{ }^{\circ} \mathrm{C}$, and the surface of the disks polished to $0.25 \mu \mathrm{m}$ for finish. To remove any mechanically induced stresses in the surface from the polishing step, the pellets were annealed at $1000{ }^{\circ} \mathrm{C}$, before dripping precursor onto the pellet surface in an amount corresponding to impregnation with the LC precursor $\left(10.6 \pm 1.0 \mathrm{mg} / \mathrm{m}^{2}\right)$, and followed by heat treatment at $650{ }^{\circ} \mathrm{C}$.

\subsection{Instruments}

The microstructure of the cathodes, before and after impregnation with the various precursors, was examined using an Autopore IV 9500V1.05 instrument (Micromeritics Instrument Corporation, Norcross, GA) for porosity and pore size distribution. BET specific surface area and pore size distribution were calculated from data collected on an Autosorb 1MP instrument (Quantachrome Instruments, FL). The samples were degassed at $300{ }^{\circ} \mathrm{C}$ for $3 \mathrm{~h}$ prior to the adsorption/desorption measurements. The BET surface area was calculated from the adsorption isotherm in the pressure ratio range $p / p_{0}$ between 0.05 and maximum 0.30 using either $\mathrm{Kr}$ or $\mathrm{N}_{2}$ adsorption at $77.35 \mathrm{~K}$. The pore size distribution was calculated from isotherms of the $\mathrm{N}_{2}$ adsorption/desorption at $77.35 \mathrm{~K}$ using the $\mathrm{BJH}$ and t-plot calculations implemented in the Autosorp 1 software. In some cases, the pore size distribution was also analyzed with $\mathrm{Kr}$ adsorption at $87.27 \mathrm{~K}$, a technique useful for analyzing pore sizes for low surface area samples with pore sizes below ca. $10 \mathrm{~nm}$ as described by Thommes [19]. These measurements were carried out with a Quantachrome AS1Win at Quantachrome, Odelzhausen, Germany.

Scanning electron microscopy (SEM) was used for studying fractured surfaces of the samples, as well as the surface of the pellets. The studies were carried out at a low accelerating voltage of $5 \mathrm{kV}$ with a high-resolution FESEM (Supra 35) and a Crossbeam 1540XB (both from Carl Zeiss, Germany).

A Bruker D8 Advance diffractometer with $\mathrm{CuK}_{\alpha}$ radiation and a PSD LynxEye detector equipped with an MRI high temperature stage was used for the in-situ HT-XRD experiments. The volume weighted mean crystallite size was calculated from the XRD diffractograms using the Double-Voigt approach, where crystallite size and strain comprise Lorentzian and Gaussian component convolutions varying in $2 \theta$ as a function of $1 / \cos \theta$ and $\tan \theta$, respectively. Diffraction data from a well 


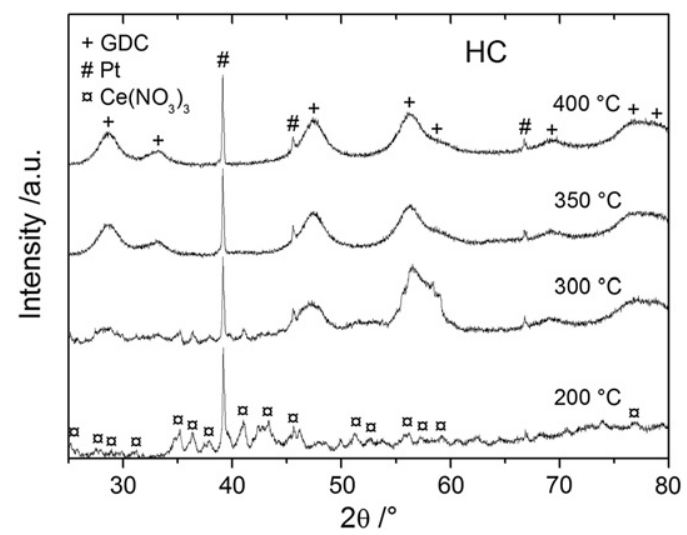

Fig. 1. In-situ XRD patterns of the precursor solution HC after heating to 200, 300, 350, and $400{ }^{\circ} \mathrm{C}$

crystallized $\mathrm{Ce}_{0.9} \mathrm{Gd}_{0.1} \mathrm{O}_{1.95}$ sample were used to derive the instrument function.

The impregnated cathode layers and the porous 8YSZ samples were tested in a symmetrical cell configuration. The cells were placed between two platinum grids that were loaded with a small weight to facilitate electrical contact between the grids and the Au current collector layers on the cell. The cells were characterized by impedance measurements at open circuit voltage (OCV), and at temperatures of $650-750{ }^{\circ} \mathrm{C}$. Measurements were collected in the frequency range from $0.05 \mathrm{~Hz}$ to $82541 \mathrm{~Hz}$, with 10 points/decade and a root mean square amplitude of $0.05 \mathrm{~V}$. The measurements were carried out in stagnant air.

\section{Results}

\subsection{In-situ HT-XRD}

The temperature at which the oxide phase formed from the precursor was identified by HT-XRD. The XRD patterns obtained for the precursor $\mathrm{HC}$ in the temperature range of $200-400{ }^{\circ} \mathrm{C}$ are shown in Fig. 1. It is seen that crystallization starts at $200{ }^{\circ} \mathrm{C}$, and the oxide phase is formed between 300 and $350{ }^{\circ} \mathrm{C}$, where the GDC peaks became well-defined. The precursors containing surfactants displayed similar behavior upon heating. Again the crystallization was observed to start at $200{ }^{\circ} \mathrm{C}$, but in these cases, the oxide phase was formed already at $300{ }^{\circ} \mathrm{C}$, as illustrated in Fig. 2 for the precursor HC-S2.

The widths of the diffractogram peaks decreased continuously from 300 to $900{ }^{\circ} \mathrm{C}$, reflecting the increasing crystallite size of the GDC particles with increasing temperature. The crystallite sizes were calculated by applying the double-Voigt approach, and Fig. 3 shows the calculated

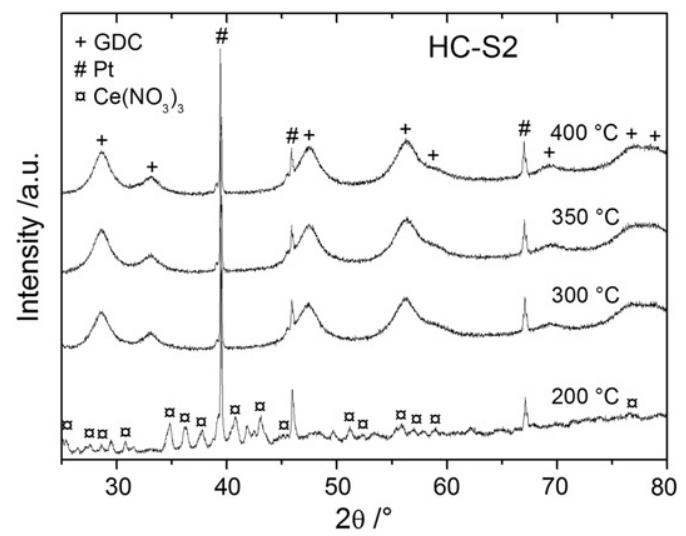

Fig. 2. In-situ XRD patterns of the precursor solution HC-S2 after heating to 200, 300, 350 , and $400{ }^{\circ} \mathrm{C}$.

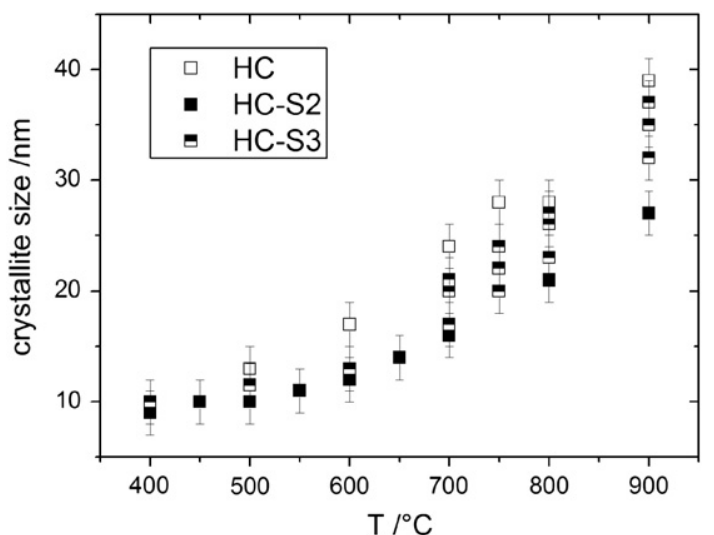

Fig. 3. GDC crystallite size as a function of temperature the HC precursor (with and without surfactants) has experienced.

crystallite size as a function of the temperature for the precursors $\mathrm{HC}$, HC-S2 and HC-S3. A tendency to slightly smaller GDC crystallites for precursors with surfactants was indicated at the intermediate temperatures between 600 and $750{ }^{\circ} \mathrm{C}$.

Since the oxide crystallite formation may differ when looking at a precursor drop on a Pt substrate, versus an impregnated porous structure [20], X-ray diffraction was also carried out on impregnated cells prepared for testing. The calculated crystallite sizes (based on peak broadening) of the impregnated cells after annealing at $300{ }^{\circ} \mathrm{C}$, and after heat treatment at $750{ }^{\circ} \mathrm{C}$ for respectively $4 \mathrm{~h}$ and $120 \mathrm{~h}$, are summarized in Table 2. After annealing at $300{ }^{\circ} \mathrm{C}$, when the oxide phase is formed, the crystallite size of the impregnated GDC was observed to be around $6-7 \mathrm{~nm}$. This matches well with the values seen for the GDC formed on the substrate after annealing at $400{ }^{\circ} \mathrm{C}$, see Fig. 3. After heat treatment at $750{ }^{\circ} \mathrm{C}$ for $4 \mathrm{~h}$, the crystallite size of the impregnated GDC increased to around $20-23 \mathrm{~nm}$ for the precursors LC and HC-S1, which is also in good agreement with the values seen for GDC on a Pt substrate (cf. Fig. 3). However, for the precursor $\mathrm{HC}$ a much smaller crystallite size is observed for the impregnated GDC compared to GDC formed on the Pt substrate at $750{ }^{\circ} \mathrm{C}$. Prolonged heat treatment at $750{ }^{\circ} \mathrm{C}$ for $120 \mathrm{~h}$ did not result in significant crystallite growth in any of the cases (cf. Table 2), which is in agreement with the self limited grain growth reported for doped ceria [21].

\subsection{Weight gain and specific surface area}

The amount of impregnated material was evaluated by the weight gain with an accuracy of $10 \%$ estimated from sample variations. The weight gain with respect to the LSM-YSZ backbone (mass or surface area) upon impregnation is seen in Tables 1 and 3. In accordance with expectations, the GDC load depends on the precursor concentration (cf. Table 1), and the number of impregnation cycles (cf. Table 3). The presence of a surfactant did not influence the impregnated amount significantly (cf. Table 1 ).

The specific surface area, measured by $\mathrm{Kr}$ and/or $\mathrm{N}_{2}$ adsorption, and normalized to the electrode mass is illustrated in Fig. 4. With the instrument accuracy being $0.15 \%$, the biggest uncertainty is related

Table 2

The crystallite size of the GDC impregnated into the LSM-YSZ backbone using different precursors, and for different heat treatments.

\begin{tabular}{llll}
\hline & \multicolumn{3}{l}{ Crystallite size in nm after heat treatment } \\
\cline { 2 - 4 } & $300{ }^{\circ} \mathrm{C}$ for $1 \mathrm{~h}$ & $750{ }^{\circ} \mathrm{C}$ for $4 \mathrm{~h}$ & $750{ }^{\circ} \mathrm{C}$ for $120 \mathrm{~h}$ \\
\hline LC & & $20 \pm 5$ & $19 \pm 5$ \\
HC & $7 \pm 2$ & $10 \pm 2$ & $10 \pm 2$ \\
HC-S1 & $6 \pm 2$ & $23 \pm 5$ & $18 \pm 5$ \\
\hline
\end{tabular}


Table 3

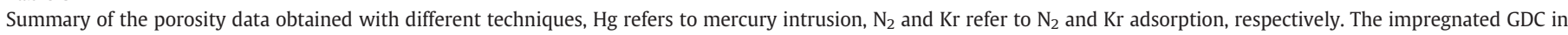
wt.\% is included for comparison. Samples of the type HC-S1 with higher amounts of infiltrated GDC (more cycles) have the extensions a and b in the name.

\begin{tabular}{|c|c|c|c|c|c|}
\hline Sample & GDC in wt.\% & Heat treatment & Porosity by $\mathrm{Hg}$ in \% & Porosity $<30 \mathrm{~nm}$ by $\mathrm{N}_{2}$ in $\mathrm{cm}^{3} / \mathrm{g}$ & Porosity $<10 \mathrm{~nm}$ by $\mathrm{Kr}$ in $\mathrm{cm}^{3} / \mathrm{g}$ \\
\hline LSM-YSZ & - & - & $16 \pm 1$ & - & 0.000415 \\
\hline $\mathrm{HC}$ & $12.2 \pm 1.2$ & - & $13 \pm 1$ & 0.008481 & 0.002469 \\
\hline $\mathrm{HC}$ & $12.2 \pm 1.2$ & $750{ }^{\circ} \mathrm{C}$ for $120 \mathrm{~h}$ & $10 \pm 1$ & - & - \\
\hline HC-S1 & $11.4 \pm 1.1$ & - & $10 \pm 1$ & 0.004877 & - \\
\hline HC-S1-a & $27.1 \pm 2.7$ & - & $8 \pm 1$ & - & - \\
\hline HC-S1-b & $30.9 \pm 3.1$ & - & $7 \pm 1$ & - & - \\
\hline HC-S1 & $11.4 \pm 1.1$ & $750{ }^{\circ} \mathrm{C}$ for $120 \mathrm{~h}$ & $8 \pm 1$ & - & - \\
\hline HC-S2 & $9.9 \pm 1.0$ & - & $10 \pm 1$ & 0.003935 & - \\
\hline HC-S3 & $12.9 \pm 1.3$ & - & $13 \pm 1$ & 0.006014 & - \\
\hline
\end{tabular}

to sample variations. Based on measurements of identically impregnated samples, an uncertainty of $10 \%$ was estimated, and for the non-impregnated LSM-YSZ backbone an uncertainty of $2 \%$ was measured. The LSM-YSZ backbone was measured to have a specific surface area of $3.16 \pm 0.06 \mathrm{~m}^{2} / \mathrm{g}$, and upon impregnation the surface area increased dramatically for all the precursors. For the low concentration precursors (with resulting lower GDC loads), the surface area increased to ca. $12 \pm 1 \mathrm{~m}^{2} / \mathrm{g}$ (for LC), and to $16 \pm 2 \mathrm{~m}^{2} / \mathrm{g}$ (for LC-S1). For the high concentration precursors, and with resulting higher GDC loads, the surface area increased even more, up to above $20 \mathrm{~m}^{2} / \mathrm{g}$.

Fig. 4 further indicates that the surfactants influence the formed surface area. Comparing the low concentration precursors (LC and LC-S1), it appears that S1 has a slight positive effect, and similarly when comparing the effect of S1 for the high concentration precursors (HC and HC-S1), whereas S2 and S3 appear to have a negative effect on the formed surface area.

Generally, the surface area per mass backbone does not vary significantly with GDC load, with the exception of the highest load with HC-S1 (cf. Fig. 4). However, as the load of GDC differs, a possible effect may not be seen when normalizing to the backbone. Thus, to further evaluate the effect of the GDC load on the surface area formation, Fig. 5 shows the surface areas normalized to the load of impregnated GDC. Using this normalization, surface areas in the range of $50-300 \mathrm{~m}^{2} / \mathrm{g}$ GDC are obtained. These values correspond well with the impregnated GDC being nano sized, and possibly having some degree of meso porosity. In contrast to Fig. 4, the highest surface area is now obtained with the low load and LC precursor, and a dramatic decrease in surface area is seen as the GDC load increases for this precursor. For the HC precursor on the other hand, a slight increase or constant surface area is seen with increasing GDC load. In Fig. 5 representation, an effect of the surfactants is also indicated. Comparing

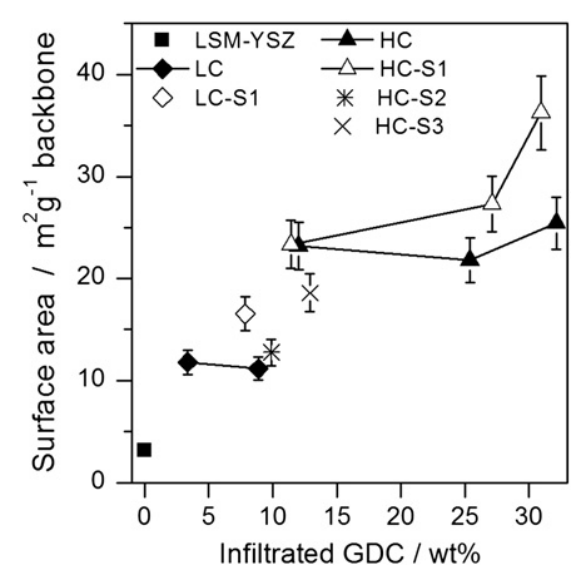

Fig. 4. The surface area normalized to the LSM-YSZ backbone mass as a function of the impregnation GDC amount. For the data point without error bar, the symbol size is representative for the error.
HC and HC-S1, higher surface areas are seen with S1, whereas S2 and S3 do not appear to have a significant effect.

The change in surface area as a function of heat treatment was also measured. Fig. 6 illustrates how the surface area decreased as the sample was exposed to heat treatment at $750{ }^{\circ} \mathrm{C}$ for 4 and $120 \mathrm{~h}$, respectively. A more rapid decrease was indicated for the samples formed with HC precursors compared to LC, and also slightly more pronounced for HC-S1. Furthermore, the main degradation appeared to occur within the first hours at $750{ }^{\circ} \mathrm{C}$, and then diminishing with time. Since crystallite growth was not detected during the heat treatment (cf. Table 2), the decrease in surface area is indicated to be related to agglomeration of the GDC nano particles upon heat treatment.

\subsection{Porosity and pore size distribution}

Pore size distributions can be evaluated by different techniques, and which is more accurate will depend on the amount of sample available for the measurement, as well as the pore size range. To evaluate which technique is more suitable, the pore size distributions were analyzed using mercury intrusion (Washburn calculation), and $\mathrm{N}_{2}$ and $\mathrm{Kr}$ adsorption/desorption isotherms (in agreement with convention, BJH calculation was used on the $\mathrm{N}_{2}$ desorption branch since no artifact from $\mathrm{N}_{2}$ appeared when comparing the isotherm adsorption/ desorption branches). Fig. 7 shows the curves obtained with the different techniques on a sample impregnated with 11 wt.\% GDC using HC precursor. The amount of meso porosity was seen to be limited, and the majority of the porosity has pore diameters above $100 \mathrm{~nm}$. Kr adsorption at $87.27 \mathrm{~K}$ is only a valid method for pore size evaluation $<10 \mathrm{~nm}$, and therefore appeared to be a less relevant technique for this kind of samples [19]. A low amount of micro porosity $(<2 \mathrm{~nm}$ pores) was also indicated by the t-plot calculations on the adsorption

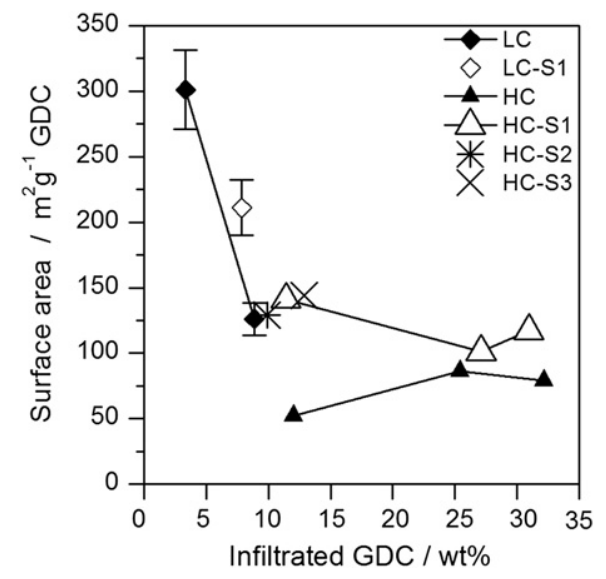

Fig. 5. The surface area normalized to the impregnated GDC mass as a function of the impregnated GDC. For data points without error bars, the symbol size is representative for the error. 


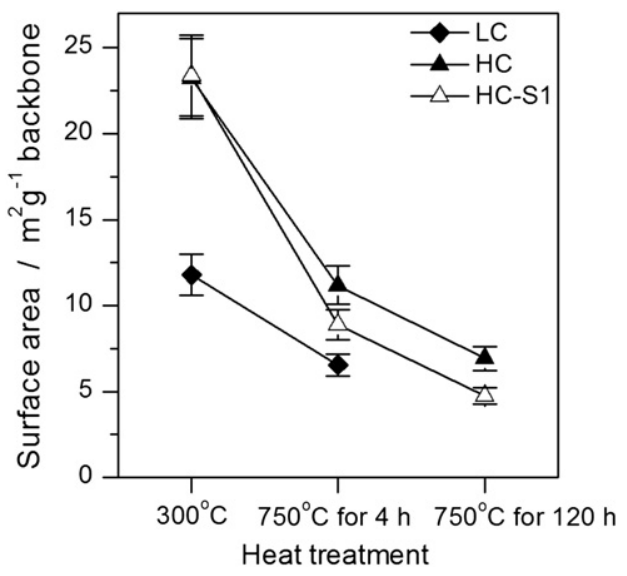

Fig. 6. The development in surface area after infiltration and exposure to different heat treatments.

isotherms, which showed calculated micro porosity volumes of around $3 \cdot 10^{-4} \mathrm{~cm}^{3} / \mathrm{g}$ compared to total gas sorption pore volumes in the range of $10^{-2} \mathrm{~cm}^{3} / \mathrm{g}$. Fig. 7 shows reasonable overlap between mercury and $\mathrm{N}_{2}$ gas sorption in the meso porous range $(<50 \mathrm{~nm})$, but since a large fraction of the porosity was in a higher pore size range, mercury intrusion appeared to be the most appropriate method for this type of samples.

The impregnated GDC load was seen to affect the pore size distribution significantly. Fig. 8 shows the pore size distributions measured by mercury intrusion for a sample before impregnation (LSM-YSZ backbone), and after infiltration with varying amount of GDC using the precursor HC-S1. Upon impregnation with $11 \mathrm{wt} . \% \mathrm{GDC}$, a minor pore volume in the meso porous range is introduced, but the main change is a reduction of the macro porosity, especially in the range of $100-200 \mathrm{~nm}$. As the GDC load is further increased, the meso porosity now again diminishes, and the macro porosity is further reduced, not only in the pore range of $100-200 \mathrm{~nm}$, but also from 200 to $300 \mathrm{~nm}$.

The quantitative decrease in total porosity upon impregnation, and the amount of introduced meso porosity as measured by mercury intrusion and $\mathrm{N}_{2}$ and $\mathrm{Kr}$ adsorption isotherms are summarized in Table 3. An effect of the surfactant on the amount of meso porosity is seen from the $\mathrm{N}_{2}$ adsorption data in Table 3. A slightly higher fraction of meso pores is measured for HC compared to HC-S3, and again for HC-S1 and HC-S2. The trends are further illustrated by the $\mathrm{N}_{2}$ adsorption curves shown in Fig. 9, obtained with BJH calculation.

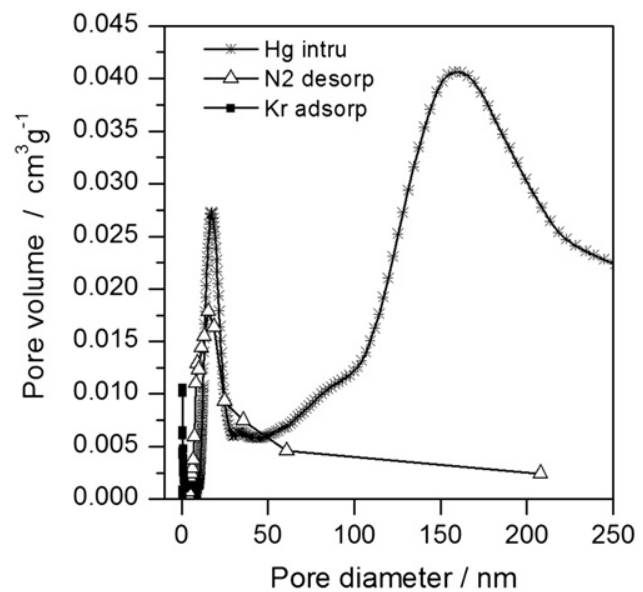

Fig. 7. Pore size distribution as measured with mercury intrusion, and $\mathrm{N}_{2}$ and $\mathrm{Kr}$ gas sorption isotherms on a sample impregnated once with the HC precursor (11 wt.\% GDC).

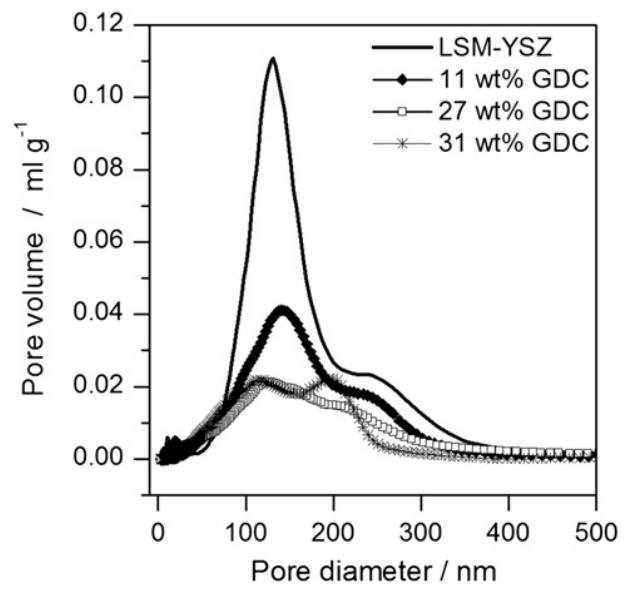

Fig. 8. Pore size distributions measured by mercury intrusion of a sample before impregnation (backbone), and after 1, 3 and 5 impregnation cycles with HC-S1.

The porosity was also seen to decrease slightly upon heat treatment. In Table 3 it is seen that the porosity of the HC sample decreased from $13 \pm 1 \%$ to $10 \pm 1 \%$ after exposure to $750{ }^{\circ} \mathrm{C}$ for $120 \mathrm{~h}$, and a similar reduction in porosity was observed for HC-S1 going from $10 \pm 1 \%$ to $8 \pm 1 \%$. Fig. 10 shows the mercury pore size distributions for the samples before and after heat treatment at $750{ }^{\circ} \mathrm{C}$ for $120 \mathrm{~h}$. From these it appears that the meso porosity coarsens upon heat treatment, and the amount of macro porosity decreases. The trends can also be explained by agglomeration of the GDC particles (in agreement with Fig. 6).

\subsection{Microscopy}

SEM micrographs of fractured surfaces before (a) and after impregnation (b-d) are shown in Fig. 11. GDC nano particles around 25-30 $\mathrm{nm}$ in diameter are formed on the backbone upon impregnation, and the number of particles, and the degree of coating of the backbone is seen to increase with higher precursor concentration and more cycles. However, differences in the nano structure as a function of presence of surfactants in the precursor, or upon heat treatment, could not be discerned with this technique. As an example, the sample impregnated with $\mathrm{HC}$ and heat treated at $750{ }^{\circ} \mathrm{C}$ for $4 \mathrm{~h}$ is shown in Fig. 11d.

Since the visual differences that were discernable appeared limited when observing fractured surfaces, a simpler 2-dimensional model

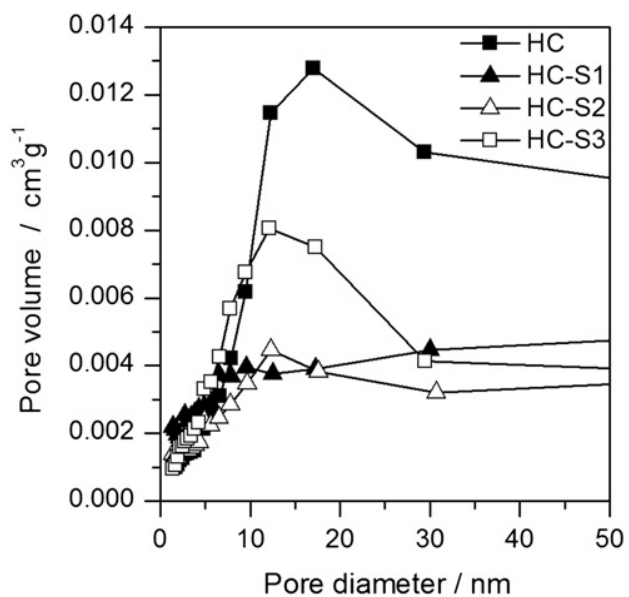

Fig. 9. Pore size distributions measured by $\mathrm{N}_{2}$ gas sorption isotherms of samples impregnated with precursors without and with different surfactants. 


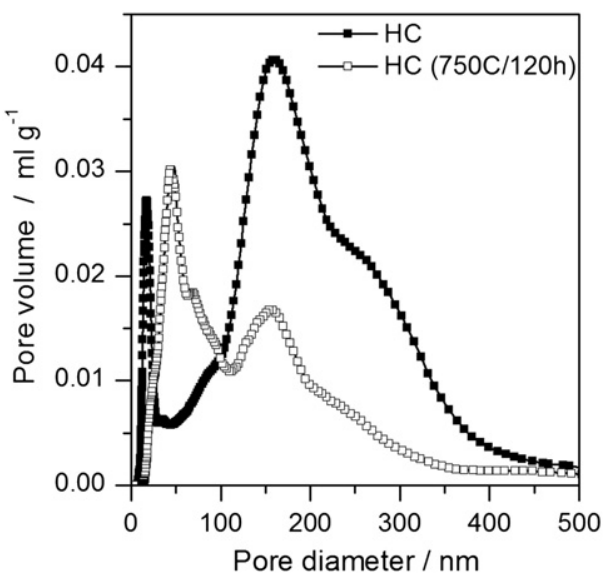

Fig. 10. Pore size distributions measured by mercury intrusion of the $\mathrm{HC}$ impregnated sample before and after heat treatment at $750{ }^{\circ} \mathrm{C}$ for $120 \mathrm{~h}$.

system was studied. Pellets of the composite LSM-YSZ powder were pressed and sintered at 1300 and $1500{ }^{\circ} \mathrm{C}$, and a precursor load corresponding to impregnation with the LC precursor was placed onto the surface as described in the Experimental section. Micrographs of the surfaces are shown in Fig. 12 for a pellet sintered at $1300{ }^{\circ} \mathrm{C}(\mathrm{a}, \mathrm{b})$, and at $1500{ }^{\circ} \mathrm{C}(\mathrm{c}, \mathrm{d})$. The density of the pellet sintered at $1500{ }^{\circ} \mathrm{C}$ was higher than for the $1300{ }^{\circ} \mathrm{C}$ sintered pellet. In both cases, the LSM and YSZ phases were easily distinguished by morphology, with the YSZ phase being smooth, and the LSM showing facetted (at $1300{ }^{\circ} \mathrm{C}$ ) or uneven (at $1500{ }^{\circ} \mathrm{C}$ ) morphology. At the interface between LSM and YSZ particles, Sr- or La-zirconates are well-known to form at temperatures above $1100{ }^{\circ} \mathrm{C}$, see e.g. $[22,23]$, however the zirconate phase was not discernable in the images here, possibly due to edge effect. The deposited GDC particles were seen to be preferentially placed on the LSM phase, and to be following the crystal facets when present, and also to be present at the interface between LSM and YSZ particles. The absence of GDC particles on the YSZ could be due to the GDC being dissolved in the YSZ. However, the maximum temperatures experienced after the GDC deposition is $650{ }^{\circ} \mathrm{C}$, and the onset of solid solution formation between GDC thin films and YSZ substrates has been reported to be $1000{ }^{\circ} \mathrm{C}$ [24]. The preferential deposition is therefore the most probably related to different surface energy and wetting of the precursor solution on LSM versus YSZ. Such a mechanism has also been described in [25].

It should be noted that the surface morphology and surface energy of the LSM-YSZ phases in the pellets may be somewhat different than in the actual electrode backbone. The pellets are sintered at higher temperatures (1300 and $1500{ }^{\circ} \mathrm{C}$ ), and then polished and annealed at $1000{ }^{\circ} \mathrm{C}$, whereas the real electrode backbone only experiences $\mathrm{ca}$. $1000{ }^{\circ} \mathrm{C}$ (cf. the Experimental section). However, it is believed that the pellets can be seen as model systems for the electrode backbone, since the pellets were also annealed at $1000{ }^{\circ} \mathrm{C}$, and the more apparent hydrophobic nature of the YSZ phase is not expected to change significantly with temperature, since same tendency is observed for the pellets sintered at 1300 and $1500{ }^{\circ} \mathrm{C}$ despite visual differences in the morphology (cf. Fig. 12b,c).

\subsection{Electrochemical impedance analysis}

Impedance spectra for a cell without impregnation (LSM-YSZ backbone), and cells with variable impregnated GDC loads, are shown in Fig. 13a. It is clearly seen that the total resistance, as well as the polarization resistance $\left(R_{p}\right)$ decreases when the load of GDC is increased.

For the case with the highest GDC load (32 wt.\%), an increase in the ohmic resistance, $R_{s}$, is seen besides the decrease in polarization resistance, $R_{p}$. The high $R_{s}$ is believed to be related to GDC from the infiltration process forming a layer on top of the sample surface, and thereby affecting the current collection between the sample surface and the $\mathrm{Pt}$ mesh in the setup. From previous measurements it was crucially observed to clean the sample surface upon each infiltration to minimize
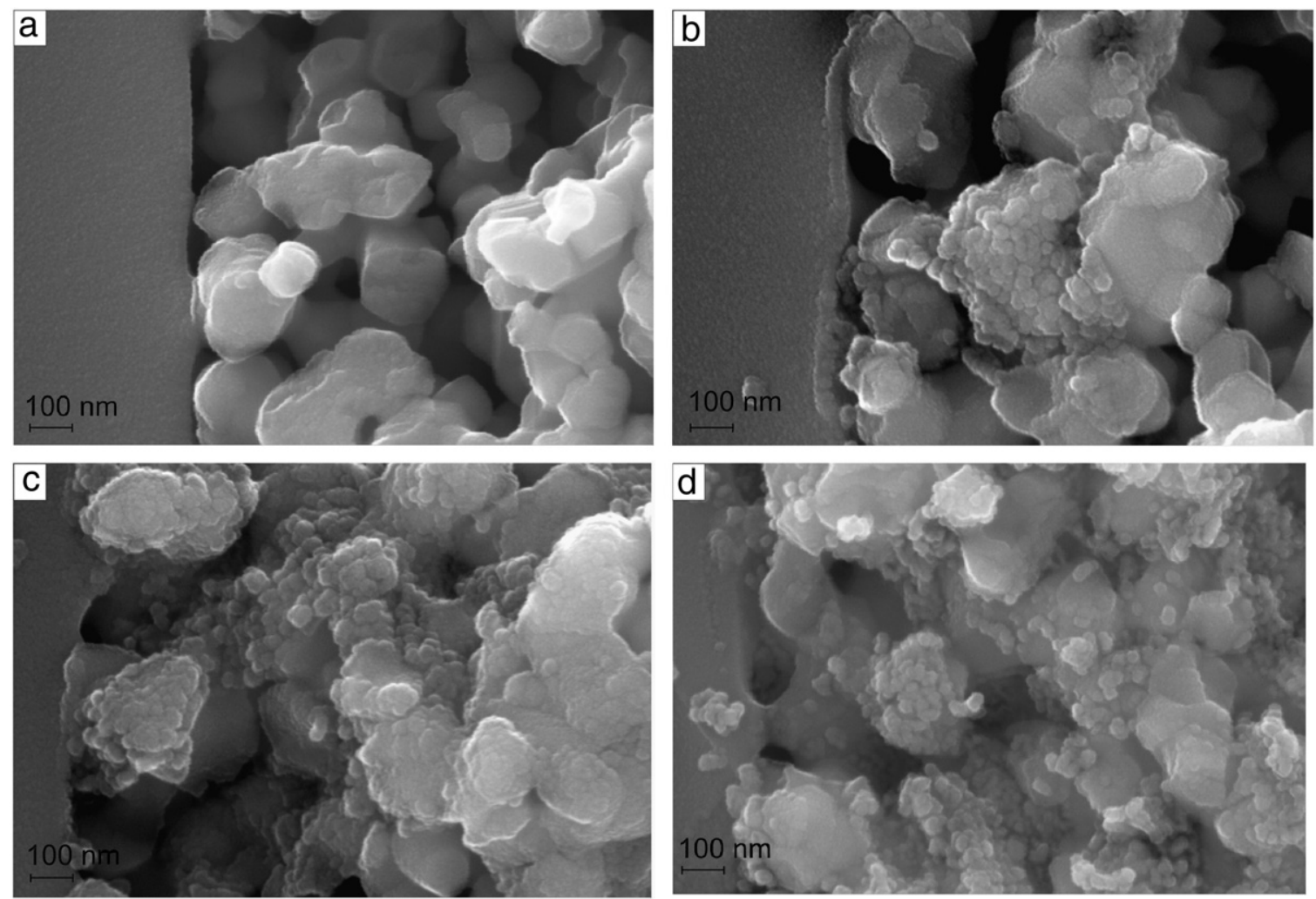

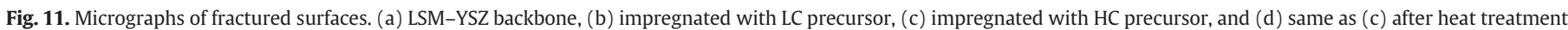
at $750{ }^{\circ} \mathrm{C} / 4 \mathrm{~h}$. 

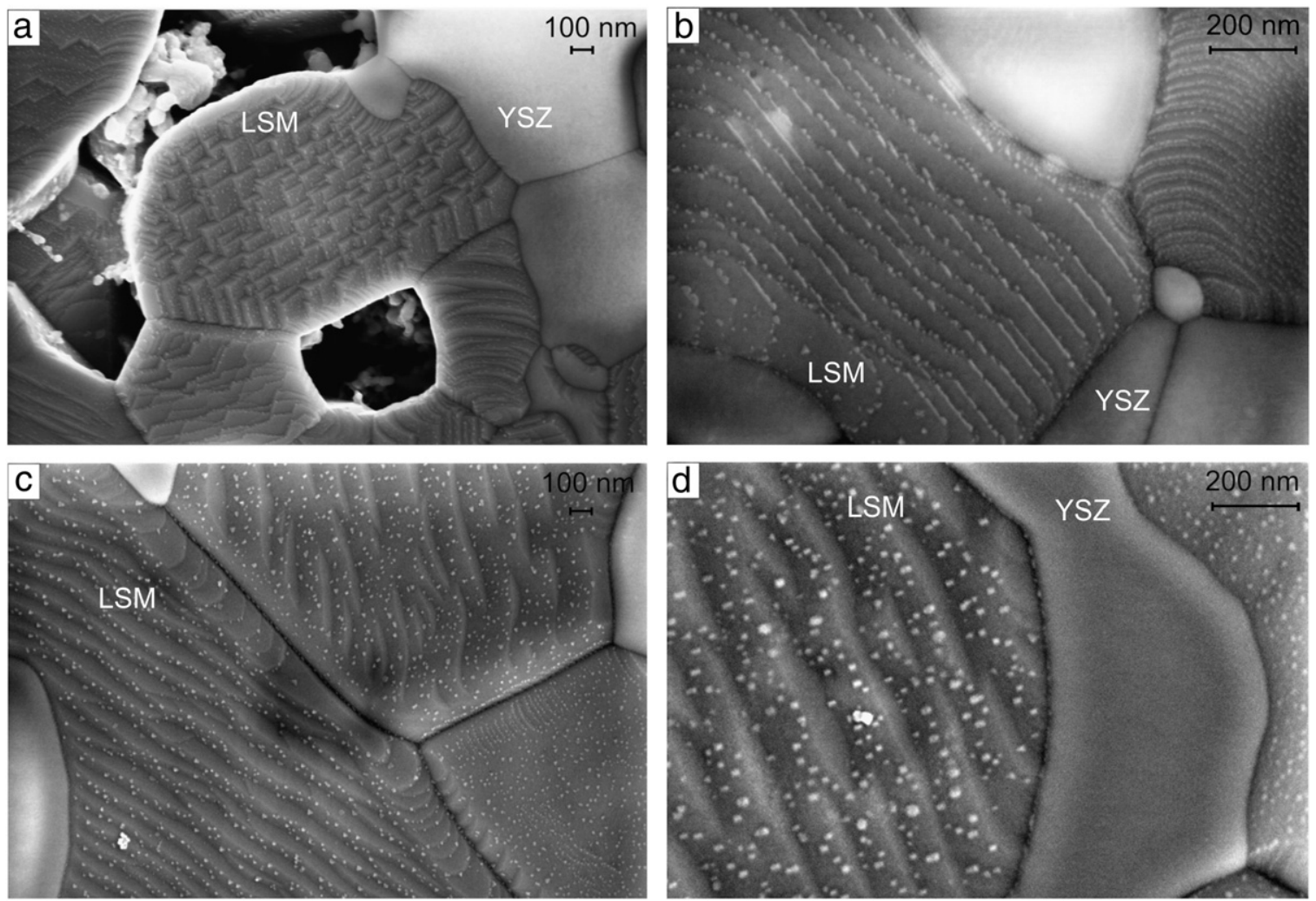

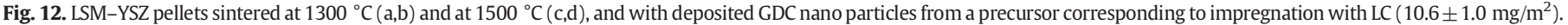

issues with $R_{s}$, especially when high loads were infiltrated. If the increase in $R_{s}$ is due to imperfect contacting (in the sense of insufficient physical contact) it could also imply an increase in $R_{p}$, as a smaller area of the cell would be utilized or active. Thus, since a clear decrease in $R_{p}$ is seen for the highest GDC loaded cell, it can be unambiguously concluded that the higher load of infiltrated GDC significantly improves a
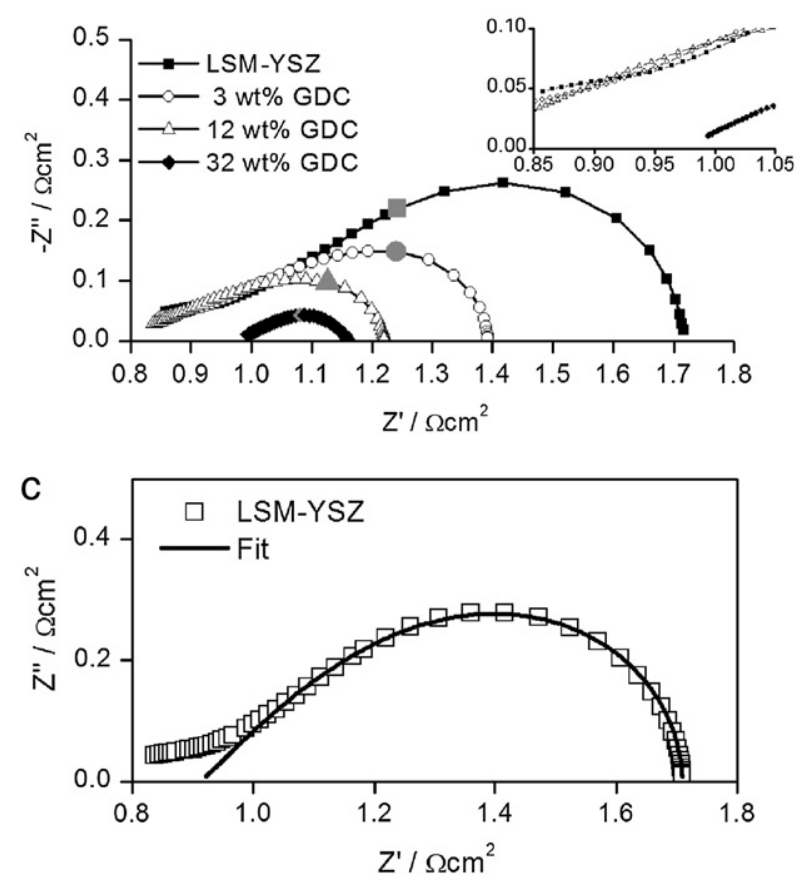
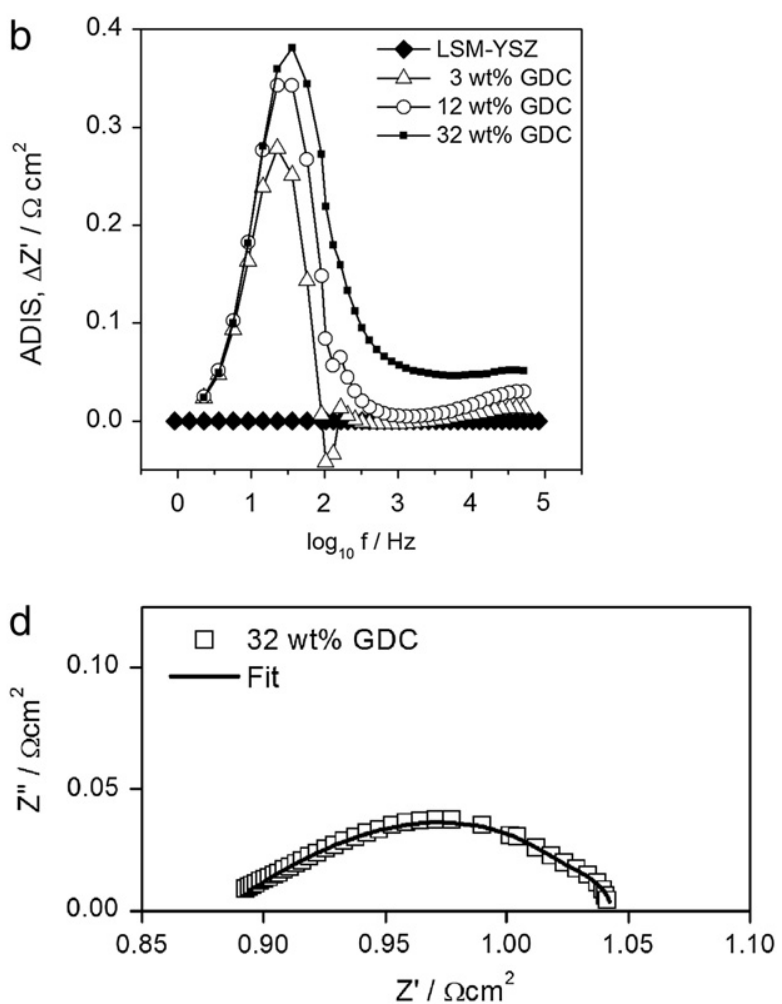

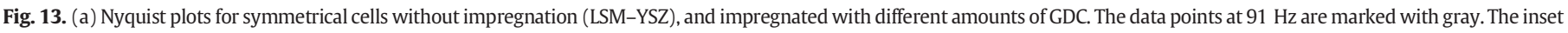

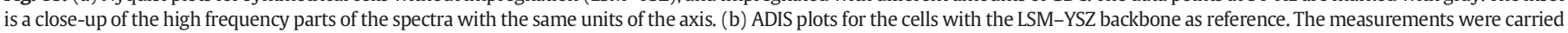
out at $650{ }^{\circ} \mathrm{C}$ in stagnant air. (c) EIS data and fit (using the model type $\mathrm{R}_{\mathrm{s}}-\mathrm{PET}-\mathrm{FLW}$ ) for the LSM-YSZ backbone, and (d) the backbone infiltrated with the highest load of GDC. 
the performance, and that the higher $\mathrm{R}_{\mathrm{S}}$ is most likely due to minor residual parts of nano sized GDC between the sample surface and the setup.

To visualize the differences between the collected impedance spectra, ADIS curves of the spectra in Fig. 13a are shown in Fig. 13b with the non-impregnated LSM-YSZ backbone taken as reference. A detailed description of the ADIS methodology can be found in [26], but in short the ADIS curves show the differences (here denoted $\Delta Z^{\prime}$ ) between the real part derivatives of two Bode spectra. From Fig. 13b it is clear that the greatest change upon infiltration is taking place around $30 \mathrm{~Hz}$, but a smaller change at higher frequencies, around $30 \mathrm{kHz}$, can also be observed.

The impedance of the LSM-YSZ composite cathode has been interpreted to consist mainly of two suppressed arcs, see reviews [27-29]. The high frequency impedance arc of the cathode is reported to have a weak or no dependency on the oxygen partial pressure, and is ascribed to be associated with the transport/transfer of oxygen intermediates/oxide ions between the LSM and the YSZ phase. In contrast, the low frequency impedance arc of the cathode is reported to have a strong dependency on the oxygen partial pressure, and is assumed to be associated with dissociative adsorption, transfer of species at and to the TPB, and surface diffusion. Reaction between the two phases of the LSM-YSZ composite is well known, and results in low conductive zirconates at the LSM-YSZ interface, which is expected to affect the high frequency arc, see e.g. reviews [27-29].

The low frequency arc of the LSM-YSZ cathode has been reported to have a characteristic frequency of $100 \mathrm{~Hz}$ at $700{ }^{\circ} \mathrm{C}$ [30]. At lower temperatures, the characteristic frequency will shift to lower values, as the resistance $(R)$ increases with decreasing temperature, and therefore will decrease the characteristic frequency of a (RQ) parallel coupling (an arc). The observed peak around $30 \mathrm{~Hz}$ at $650{ }^{\circ} \mathrm{C}$ is therefore in accordance with the previous observations. The peak at $30 \mathrm{~Hz}$ further indicates that it is mainly the electrochemical reaction taking place at or close to the TPB, which is improved with the infiltration of GDC.

Besides the clear decrease in resistance observed in the Nyquist plots in Fig. 13a, a change in the shape of the spectra as a function of the GDC load can also be discerned. For the cell with the highest GDC load (32 wt.\%), a feature appears at low frequencies, which can be interpreted to be associated with the gas concentration impedance. For symmetrical cells with SOFC cathodes in stagnant air, the gas concentration impedance is usually around $0.04 \Omega \mathrm{cm}^{2}$ [31], which is in accordance with low frequency feature observed in the present study. The gas concentration impedance can only be resolved if the polarization resistance is sufficiently small, as in the case with $32 \mathrm{wt} . \%$ GDC.

The predominant shape change in Fig. 13a as a function of the GDC load is seen to be located in the high frequency region. As mentioned previously, LSM-YSZ cathodes are in the reviews [27-29] interpreted to consist of mainly two (RQ) impedance arcs. The interpretations were based on measurements in the higher-temperature range of $700-900{ }^{\circ} \mathrm{C}$ (the believed relevant operational temperature for SOFC at that time). However, in that temperature range there is a strong overlap between impedance contributions, and thus only two (RQ) impedance arcs are required to satisfactorily fit the impedance response. From studies of the LSM-YSZ impedance at lower temperature ranges $\left(300-700{ }^{\circ} \mathrm{C}\right)$, it is clear that the system is more complex $[32,33]$. Here, at least three (RQ) arcs were needed to account for the electrochemical impedance of the cathode. In Fig. 13a, the LSM-YSZ backbone spectrum shows a partly resolved suppressed semicircle at high frequencies followed by a response, which can be described as a skewed semicircle (at the lower frequencies). This response at $650{ }^{\circ} \mathrm{C}$ is in excellent accordance with the mentioned low temperature studies [32,33].

In the mentioned low temperature studies it was also seen that the skewed semicircle response changed shape into a semicircle upon further lowering of the temperature from $700{ }^{\circ} \mathrm{C}$ to $300{ }^{\circ} \mathrm{C}$. Such characteristics are predicted by classic porous electrode theory (PET), see review in [34]. Physically, the transition in shape reflects that the electrochemical utilization thickness exceeds the thickness of the electrode, and this situation results in the response of a suppressed semicircle. The PET response is valid for porous electrodes consisting of both an ionic and an electronic connected network, such as the LSM-YSZ composite cathode. The PET describes the coupling between the ionic conduction in the YSZ composite backbone with the electrochemical reaction at the TPB within the porous composite cathode. The response has recently been used in solid state electrochemistry to account for the impedance of the conventional Ni-YSZ cermet anode [35].

The data from this study was fitted using a serial combination between a serial resistance $R_{s}$, the PET impedance response and a Finite-Length-Warburg (FLW) impedance element $\left(R_{S}-P E T-F L W\right)$. The latter element is included to account for the oxygen gas diffusion. The model implies that the ionic conductivity of the LSM-YSZ composite is modeled as a resistor pr. unit thickness, and the electrochemical reaction at the TPB within the porous composite cathode as a resistor in parallel with a constant phase element (CPE). For further details on these aspects, the reader is referred to the mentioned references [34,35]. The fit results are seen in Fig. 13c-d for sister samples of the non-infiltrated backbone (LSM-YSZ) and the cell with $32 \mathrm{wt}$ \% GDC. The model is seen to describe the backbone spectra well, except for an additional high frequency response (cf. Fig. 13c), whereas a good fit of the whole frequency spectra is obtained for the infiltrated cell. The different fits of the high frequency response indicates that it is associated with the previously mentioned transport/transfer of oxygen intermediates/oxide ions between the LSM and the YSZ phase, and in this connection, also to the presence of low conductive zirconates at the interface (seen as the additional high frequency response of the LSM-YSZ backbone). Upon infiltration with GDC, the GDC placed at the TPB will shunt the high frequency LSM-YSZ interfacial impedance response by providing an alternative reaction route. Instead of oxygen reduction at the LSM phase near TPB combined with oxide ion transport through YSZ, the oxygen reduction can take place at the LSM-GDC followed by oxide ion transport through the infiltrated GDC, and then into the YSZ. The effect of the interfacial zirconates will be reduced with increasing GDC load, corresponding to the disappearance of the partly resolved high frequency arc, and the remains will be a skewed semicircle-like shape, as seen for the highest GDC loaded cell. The data suggests therefore, that the GDC infiltration provides a way to reduce the effect of zirconate formation by extending the TPB length.

The electrochemical effect of annealing the cell at $750{ }^{\circ} \mathrm{C}$ was also tested at the end of the tests (not shown here). After exposure to $750{ }^{\circ} \mathrm{C}$ for up to $16 \mathrm{~h}$, a small degradation was observed, ca. $0.03 \Omega \mathrm{cm}^{2}$ (at $750{ }^{\circ} \mathrm{C}$ ), corresponding to a relative degradation of less than $10 \%$ in both cases, which is in the same range as the sample reproducibility.

A minor electrochemical effect of the precursor surfactant was indicated. Fig. 14a shows the Nyquist plot for cells impregnated with HC, HC-S1, and HC-S2 (i.e. ca. 11-12 wt.\% GDC), and Fig. 14b shows the corresponding ADIS plots with HC taken as reference. Also in this case, the difference between the spectra was in the low frequency range with a characteristic frequency of around $30 \mathrm{~Hz}$. The best performance was observed with the precursor HC-S2, which also was observed to form GDC with minimum meso porosity (cf. Table 3). However, the changes in the spectra are minor and within the $10 \%$ uncertainty.

The conductivity of the impregnated GDC phase was evaluated by measurements on infiltrated model backbones consisting of only YSZ (to avoid the highly electronic conducting LSM phase). This was done by measuring the impedance of the porous YSZ before and after infiltration with GDC, and the difference in conductivity between the YSZ and the infiltrated YSZ is ascribed to the infiltrated GDC phase. This model system will most likely provide an underestimation of the contribution of the GDC phase, since the porosity of the YSZ is a bit higher than for the LSM-YSZ ( $27 \pm 1 \%$ versus $16 \pm 1 \%$ ), and due to 

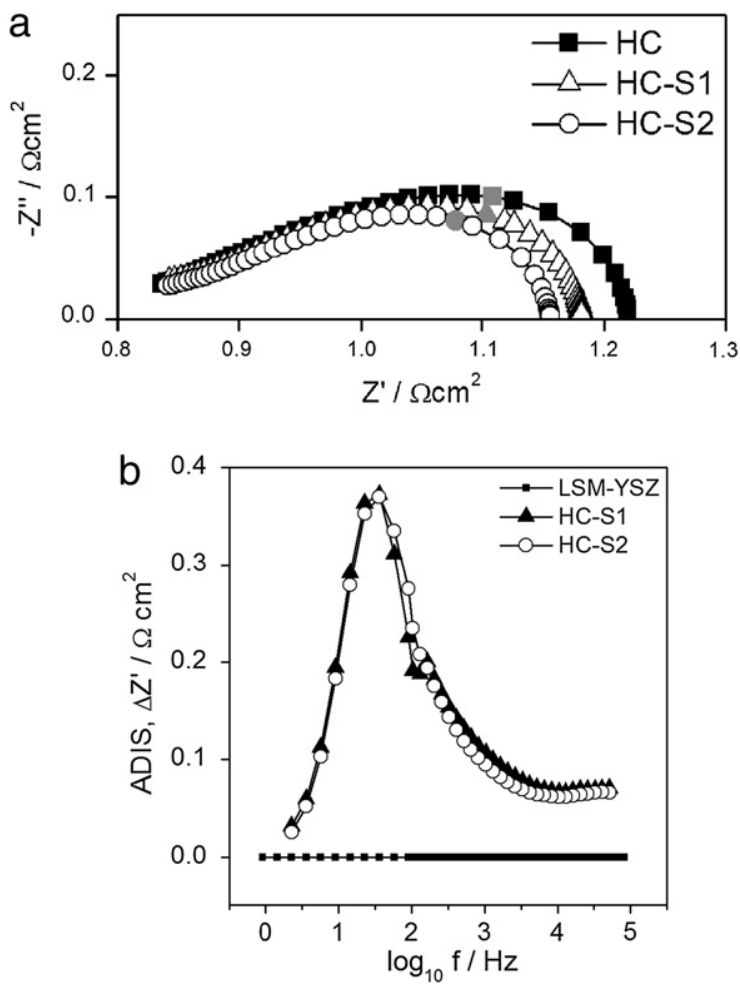

Fig. 14. (a) Nyquist plots of cells impregnated once with the precursor without surfactant (HC), and with surfactants (HC-S1 and HC-S2). The data point at $131 \mathrm{~Hz}$ is marked with gray in the spectra. (b) ADIS plots (here denoted $\Delta Z^{\prime}$ ), showing the real part derivatives of the Bode spectra with LSM-YSZ as reference. The measurements were carried out at $650{ }^{\circ} \mathrm{C}$ in stagnant air.

the apparent more hydrophobic nature of YSZ compared to LSM (i.e. the formed GDC will be less well-distributed, cf. the Discussion section). However, the model system provides a relative measure of the GDC contribution to the ionic conductivity of the backbone as a function of the impregnate loading, as well as it takes the effect of the formed micro and meso porosity in the GDC into account. The impedance of the porous YSZ samples was measured at different temperatures between 450 and $750{ }^{\circ} \mathrm{C}$, and Fig. 15 shows typical plots illustrated by YSZ impregnated with HC precursor. The Nyquist plot is seen to be comprised of at least two arcs, most visible at the lower temperatures, with the high frequency arc being related to the electrolyte (i.e. the YSZ-GDC phase, including grain interior and grain boundary contributions), and the low frequency arc being related to the Au electrodes, as also described in [36]. Thus, the total ionic conductivity of the YSZ-GDC structure can be deduced by fitting the intercept of the two arcs. Based on this, the total conductivity was calculated, and the values for the YSZ reference and impregnated

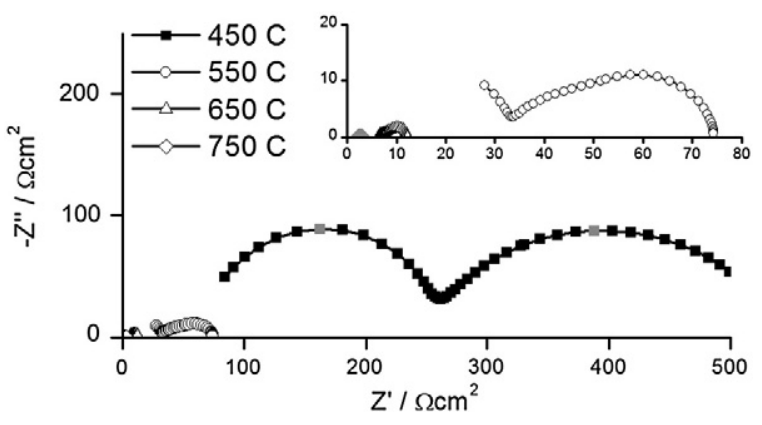

Fig. 15. Nyquist plots at different temperatures for a porous YSZ sample impregnated once with the $\mathrm{HC}$ precursor. Due to the strong temperature dependence only the spectra at $450{ }^{\circ} \mathrm{C}$ and $550{ }^{\circ} \mathrm{C}$ (inset in right corner with the same units of the axis) are clearly shown. The data points marked with gray show $39 \mathrm{~Hz}$ and $21 \mathrm{kHz}$.
Table 4

The measured conductivity at $650{ }^{\circ} \mathrm{C}$ of porous YSZ, and porous YSZ impregnated with GDC using the precursor solution HC.

\begin{tabular}{lll}
\hline Sample & GDC in wt\% & Conductivity at $650{ }^{\circ} \mathrm{C}$ in $\mathrm{S} / \mathrm{cm}$ \\
\hline YSZ & - & $0.0034 \pm 0.0002$ \\
YSZ & $10 \pm 1.0$ & $0.0033 \pm 0.0002$ \\
YSZ & $26 \pm 2.6$ & $0.0038 \pm 0.0001$ \\
YSZ & $31 \pm 3.1$ & $0.0039 \pm 0.0001$ \\
\hline
\end{tabular}

samples at $650{ }^{\circ} \mathrm{C}$ are summarized in Table 4 , and the contribution in conductivity from the impregnated GDC nano phase is the difference in total conductivity between the impregnated and the reference (i.e. non-impregnated) sample. From Table 4 it is seen that the difference is significant, and the slightly higher conductivity for the samples with higher GDC load is most likely associated with percolation of the GDC phase, and the decrease in porosity by ca. $1 \%$ (cf. Table 3 ).

\section{Discussion}

In the current study, the impregnation of GDC nano particles in LSM-YSZ electrodes was used as an example to characterize factors on the formed nano structures.

\subsection{Effect of surfactants}

The presence of a surfactant in the precursor solution appeared to have a minor effect on the formed microstructure, as well as a minor or insignificant effect on the electrochemical performance.

The surfactants were observed to decrease the oxide formation temperature with ca. $50{ }^{\circ} \mathrm{C}$ (cf. Figs. 1, 2), and also slightly finer GDC crystallite sizes were indicated for precursors with surfactants between 600 and $750{ }^{\circ} \mathrm{C}$ (cf. Fig. 3). In literature it has been reported how surfactants may act as complexing reagents in the formation of complex perovskites from aqueous solutions of the salts, and thereby facilitate the formation of the pure perovskite phase due to controlled precipitation. An associated effect of the surfactant is a more uniform distribution of the nano particles in the impregnated structure [1]. In the current study with GDC, it was also indicated that the surfactants influenced the starting point of precipitation.

The surfactant did not appear to have an effect on the formed meso porosity. The highest fraction of meso porosity was observed for the precursor without surfactant (HC), which contained ca. twice as high volume meso porosity as the structures formed with Triton X-100 and P123 (HC-S1 and HC-S2), and the structure with Triton X-45 (HC-S3) displayed a meso porosity volume in-between these (cf. Table 3 and Fig. 9). From the literature it is known that surfactants forming micelles can act as templates for ordered meso structures, or act as aggregated molecular "spacers" creating less ordered meso pores. The first case generally requires slow and rate controlled oxide formation [37], whereas the latter has been obtained with quick and direct calcination [38]. In both cases, for the surfactants to interact and act as pore shaping agents, the concentration must be above the CMC. For the surfactant P123, the concentration typically chosen in the literature is $1 \mathrm{~g} \mathrm{P} 123$ per $10 \mathrm{~g}$ organic solvent [38,39], which is far above the CMC values reported in [16] of $0.04-0.4 \mathrm{mg} / \mathrm{mL}$. In the current study, surfactant concentrations between 0.4 and $0.6 \mathrm{~g}$ per $10 \mathrm{~g}$ solvent were chosen, which is also high above the respectively reported CMC's, and quick calcinations were done directly at $300{ }^{\circ} \mathrm{C}$ (cf. the experimental section). However, for micelles and templating to occur it is not enough to be above CMC, the solution also needs to be between the Krafft temperature and cloud point of the solution (which is system specific, i.e. depending on surfactant, solvent, salts present, concentration of the components), and furthermore, sufficient time for the organization to occur is needed. The lack of a dominating surfactant templating effect indicates that micelles are not formed with the current impregnation 

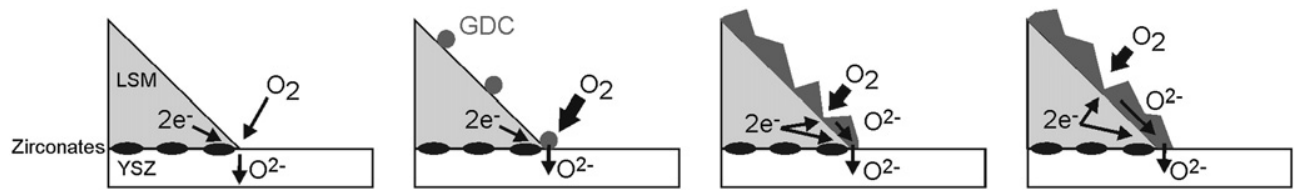

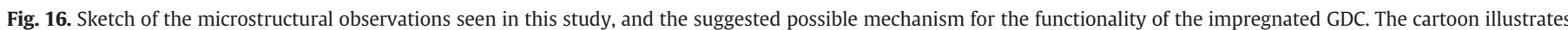
the position and effect of the GDC with increasing GDC load going to the right. The reaction and transport rates are illustrated with the arrows.

protocol, and points to the main function of the surfactant being improved wetting of the solution on the backbone.

An important feature in the impregnated nano structures is the distribution uniformity of the nano particles. The wetting and the uniformity have been correlated for various systems [1,37] and references in these. The suggested improved wetting obtained with surfactants, matches with the observed slightly smaller GDC crystallites in the cases with surfactant (cf. Fig. 3). The quick calcination, done directly at $300{ }^{\circ} \mathrm{C}$, is also likely to contribute to the uniformity. From heterogeneous catalyst preparation, it is known that quick drying rates minimize capillary flow of the impregnated precursor [40], and Zhao et al. [20] reported how faster calcination rates promoted the nucleation and produced finer and a well-connected impregnated phase. To fully verify the hypothesis of the surfactant effect in the current study, contact angle measurements or experiments with slower calcination rates could also be carried out, but has not been included in this study.

From the electrochemical characterization it was indicated that the performance was slightly affected by the presence of a surfactant in the precursor (cf. Fig. 14). Slightly better performance in the electrochemical frequency range $(10-100 \mathrm{~Hz})$ was obtained with HC-S2 precursor, and this effect could be related to a more uniform distribution, and also correlate to a lower amount of meso porosity (cf. Table 3 ). The observed trend cannot be a reflection of differences in the GDC load as the load was similar (10-13 wt.\%) and with the lowest load for HC-S2 (cf. Table 3).

\subsection{Effect of GDC load}

The electrochemical characterization displayed a clear correlation between performance and impregnated GDC load (cf. Fig. 13). The introduction of GDC nano particles was associated with an increase in the total electrode surface area, which went from ca. 3 up to ca. $35 \mathrm{~m}^{2} / \mathrm{g}$ LSM-YSZ backbone (cf. Fig. 4). However, the formed surface area did not appear correlated to the GDC load. For the low concentration precursor (LC), the formed GDC surface area decreased until the GDC load was similar to the HC samples, and for HC samples the formed GDC surface was almost constant irrespective of the GDC load (cf. Fig. 5). According to the micrographs in Fig. 11, the GDC forms agglomerates that are coating the backbone rather than well-dispersed nano particles, and the surface area measurements indicate that a coating-like layer is obtained at around $10 \mathrm{wt}$.\% infiltrated GDC. Once a coat can be formed, any additional GDC nano particles introduced will pack within and on top of the layer, thereby decreasing the inter-particular meso porosity, and forming a multi-layer like coat that displays a similar surface area. The interpretation can be supported by the measured pore size distributions, where the meso porosity was seen to disappear with increasing GDC load (cf. Fig. 8). Furthermore, it was observed that the porosity decreased (cf. Table 3), and the pores with pore diameter $<300 \mathrm{~nm}$ were clogging up (cf. Fig. 8) with the increasing GDC load.

Whereas the higher GDC load and better performance cannot be correlated to the specific surface area, they appear correlated to the density of the GDC layer (cf. Table 3) and was indicated to be correlated with the connectivity/percolation of the GDC layer (cf. Table 4). The observations indicate that the main function of the GDC is to extend the TPB zone by acting as an additional ionic network on top of the LSM surface and at the LSM-YSZ interface.
Upon annealing at $750{ }^{\circ} \mathrm{C}$ the surface area was seen to decrease and almost reverse to the original surface area of the backbone (cf. Fig. 6). The annealing was associated with limited GDC crystallite growth and performance loss, and also the performance loss was limited. The apparent stability of the GDC nano particles is ascribed to the self limiting growth of doped ceria, and only agglomeration of the GDC particles therefore occurs (reducing the surface area, and creating more uniform pore size distribution, cf. Fig. 10). The limited sensitivity of the performance to agglomeration can be explained by the agglomeration occurring without affecting the ionic conductivity and the network extension of the GDC phase significantly.

\subsection{The functionality of impregnated GDC}

In the current study, the main electrochemical response upon GDC infiltration was seen around a frequency of $30 \mathrm{~Hz}$, which fitted well with the characteristic frequency of LSM-based cathodes reported previously, and which indicated that it is mainly the electrochemical reaction taking place at or close to the TPB (i.e. transfer of species at the TPB), which is improved with the infiltration of GDC.

A change in the high frequency response was also observed, and reflected as a change in the shape of the high frequency part of the spectra upon infiltration with GDC. Using classical PET, the change in shape could be explained and related to the infiltrated GDC placed at the TPB shunting the high frequency LSM-YSZ interfacial impedance response.

The electrode process was seen to improve significantly with the GDC load, and also indicated to correlate with the density and connectivity of the GDC phase. The observations seen in this study are sketched in Fig. 16. The figure also illustrates the hypothesis, or suggested possible mechanism for the functionality of the impregnated GDC, which was indicated by the observations in the present study. In the nonimpregnated electrode (cf. Fig. 16, left image), the reaction sites are restricted to the TPB zone, defined mainly by the transport of the oxide species on the LSM. Low conductive phases (zirconates) at the LSM-YSZ interface are shown with black. At low GDC loads (cf. Fig. 16, 2nd image from left), the GDC nano particles form isolated clusters/agglomerates (in agreement with Fig. 12), resulting in the large increase in surface area. However, only the GDC particles placed at the TPB can have an electrochemical shunting effect. In addition, the impregnated nano sized GDC may act as a catalyst itself, or increase the LSM catalytic activity through the NEMCA or spillover effect. As the GDC load increases (cf. Fig. 16, 3rd and 4th image from left), a coat with constant surface area is formed, the GDC becomes percolated, and the porosity of the GDC layer decreases. Improved performance is then obtained due to the extension of the TPB due to the ionic conductivity in GDC. At the higher loadings, the GDC network forms a complete ionic conducting bypass around the zirconate phase.

\section{Conclusions}

The composite LSM-YSZ cathodes impregnated with GDC are characterized by an electrochemical improvement at a characteristic frequency of ca. $30 \mathrm{~Hz}$. The electrode process was observed to correlate with the GDC load, and to the density and connectivity of the GDC, whereas the surface area of GDC was only correlated to the performance for low GDC loads. The functionality of the GDC was mainly 
related to an extension of the TPB, created by the ionic conducting GDC network on top of the LSM particles and zirconate phases. The investigations show that tailoring of the impregnated structure is an important parameter, if the full potential of impregnated electrodes is to be obtained.

\section{Acknowledgments}

This work was supported financially by the Department of Energy Conversion and Storage, Technical University of Denmark. Part of this work was further supported by Topsoe Fuel Cell A/S and the Danish National Advanced Technology Foundation. The authors are grateful to Dr. Carsten Blum and Helmut Gronegger at Quantachrome, Germany, for performing the $\mathrm{Kr}$ adsorption measurements at $87.27 \mathrm{~K}$. The authors also thank the technical staff at the Department of Energy Conversion and Storage for technical support in sample fabrication and characterization.

\section{References}

[1] Z. Jiang, C. Xia, F. Chen, Electrochim. Acta 55 (2010) 3595-3605.

[2] S.P. Jiang, Int. J. Hydrogen Energy 37 (2012) 449-470.

[3] S.P. Jiang, Y.J. Leng, S.H. Chan, K.A. Khor, Electrochem. Solid-State Lett. 6 (2003) A67-A70.

[4] S.P. Jiang, W. Wang, J. Electrochem. Soc. 152 (2005) A1398-A1408.

[5] Z. Liu, D. Ding, B. Liu, W. Guo, W. Wang, C. Xia, J. Power. Sources 196 (2011) 8561-8567.

[6] M. Mogensen, M. Søgaard, P. Blennow, K.K. Hansen, In: Lucerne Fuel Cell Forum, Switzerland, 2008, p. A0402, paper.

[7] F. Bidrawn, G. Kim, N. Aramrueang, J.M. Vohs, R.J. Gorte, J. Power. Sources 195 (2010) 720-728.

[8] C. Knöfel, H.-J. Wang, K.T.S. Thydén, M. Mogensen, Solid State Ionics 195 (2011) 36-42.

[9] M. Backhaus-Ricoult, K. Adib, T. St.Clair, B. Luerssen, L. Gregoratti, A. Barinov, Solid State Ionics 179 (2008) 891-895.

[10] A. Babaei, S.P. Jiang, J. Li, J. Electrochem. Soc. 156 (2009) B1022-B1029.

[11] K. Streletzky, G.D.J. Phillies, Langmuir 11 (1995) 42-47.

[12] E. Gonick, J.W. McBain, J. Am. Ceram. Soc. 69 (1947) 334-336.

[13] Z. Wang, J.-H. Xu, W. Zhang, B. Zhuang, H. Qi, Colloids Surf. B Biointerfaces 61 (2008) $118-122$.
[14] R.W. Egan, M.A. Jones, A.L. Lehninger, J. Biol. Chem. 251 (1976) 4442-4447.

[15] S.K. Hait, S.P. Moulik, J. Surfactants Deterg. 4 (2001) 303-309.

[16] Y.-L. Su, H.-Z. Liu, Korean J. Chem. Eng. 20 (2003) 343-346.

[17] J. Jansson, K. Schillén, G. Olofsson, R. Cardoso da Silva, W. Loh, J. Phys. Chem. B 108 (2004) 82-92.

[18] T. Klemensø, K. Thydén, M. Chen, H.-J. Wang, J. Power. Sources 195 (2010) 7295-7301.

[19] M. Thommes, Quantachrome Instruments Powder Tech Note 39, February 2006

[20] F. Zhao, Z. Wang, M. Liu, L. Zhang, C. Xia, F. Chen, J. Power. Sources 185 (2008) 13-18.

[21] J.L.M. Rupp, A. Infortuna, L.J. Gauckler, Acta Mater. 54 (2006) 1721-1730.

[22] A. Mitterdorfer, L.J. Gauckler, Solid State Ionics 111 (1998) 185-218.

[23] C. Chatzichristodoulou, M. Chen, J.R. Bowen, L. Yi-Lin, J. Am. Ceram. Soc. 93 (2010) 2884-2890.

[24] X.D. Zhou, B. Scarfino, H.U. Anderson, Solid State Ionics 175 (2004) 19-22.

[25] S. Lee, N. Miller, H. Abernathy, K. Gerdes, A. Manivannan, J. Electrochem. Soc. 158 (2011) B735-B742.

[26] S.H. Jensen, A. Hauch, P.V. Hendriksen, M. Mogensen, N. Bonanos, T. Jacobsen, J. Electrochem. Soc. 154 (2007) B1325-B1330.

[27] M.J. Jørgensen, M. Mogensen, J. Electrochem. Soc. 148 (2001) A433-A442.

[28] S.P. Jiang, J. Mater. Sci. 43 (2008) 6799-6833.

[29] S.B. Adler, Chem. Rev. 104 (2004) 4791-4843.

[30] R. Barfod, M. Mogensen, T. Klemensø, A. Hagen, Y.L. Liu, P.V. Hendriksen, J. Electrochem. Soc. 154 (2007) B371-B378.

[31] J. Nielsen, T. Jacobsen, M. Wandel, Electrochim. Acta 56 (2011) 7963-7974.

[32] N. Bonanos, P. Holtapples, M.J. Jørgensen, In: Lucerne Fuel Cell Forum, Switzerland, 2002, pp. 578-585.

[33] In: N. Bonanos, B.C.H. Steele, E.P. Butler, E. Barsoukov, J.R. McDonald (Eds.), Impedance Spectroscopy-Theory, Experiment, and Application, John Wiley \& Sons Inc., Hoboken, NJ, 2005, pp. 258-263.

[34] In: A. Lasia, M. Schlesinger (Eds.), Modern Aspects of Electrochemistry, vol. 43, Springer, 2009, pp. 67-138.

[35] V. Sonn, A. Leonide, E. Ivers-Tiffée, J. Electrochem. Soc. 155 (2008) B675-B679.

[36] V. Singh, S. Babu, A.S. Karakoti, A. Agarwal, S. Seal, J. Nanosci. Nanotechnol. 10 (2010) 1-9.

[37] R. Chao, J.R. Kitchin, K. Gerdes, E.M. Sabolsky, P.A. Salvador, ECS Trans. 35 (2011) 2387-2399.

[38] M. Lundberg, B. Skårman, F. Cesar, L.R. Wallenberg, Microporous Mesoporous Mater. 54 (2002) 97-103.

[39] P. Yang, D. Zhao, D.I. Margolese, B.F. Chmelka, G.D. Stucky, Nature 396 (1998) 152-155.

[40] A.V. Nelmark, L.I. Kheifez, V.B. Fenelonov, Ind. Eng. Chem. Prod. Res. Dev. 20 (1981) 439-450. 